\title{
Implication of Ethics in Supply Chain Function
}

\author{
Sunday Agbor Mbu a,* and Maurice Ayuketang Nso ${ }^{b}$ \\ a Department of Economics and Management Sciences, University of Buea, Cameroon \\ b Higher Institute of Commerce and Management, The University of Bamenda, Cameroon \\ *Corresponding author Email: mbusa10@yahoo.com \\ DOI: https://doi.org/10.34256/ajir2135
}

Received: 03-07-2021; Revised: 26-09-2021; Accepted: 28-09-2021 Published: 30-09-2021

\begin{abstract}
This research study examines the importance of ethics in supply chain management functions. The data sample consisted of 30 respondents collected using a questionnaire administered randomly to firms' employees or representatives. Results show, there is no strong and sufficient evidence to infer the existence of unethical behaviours and the significance of ethics in a supply chain function within the players or parties in a supply chain relationship. Thus, this study recommends that parties in a supply chain relationship should act ethically right for long lasting relationship within the supply chain functions in firms or companies. Essentially all businesses to including banking and non-banking firms have needs that require the use of supply chains. have responsibilities that require the use of supply chains. Therefore, the outcome of this study is useful applicable to all sorts of business entities.
\end{abstract}

Keywords: Ethics, Supply Chain, Supply Chain Ethics, Supply Chain function, Buyers, Suppliers

\section{Introduction}

Does ethics have implications in supply chains? If Yes, then what could be the implications of ethics in a supply chain function? These are the questions that this study is set to answer. Ethics has for long been acknowledged by supporters and admirers from both small and large organisations (Jermsittiparsert and Srihirun, 2019). Ethics prescribed principles that guide humans and guide the way humans conduct at work places and job places and functions. Concepts such as respect, trust, fairness, integrity, diligence, honesty, probity are central to ethical atmosphere, to including avoidance of conflict and abuse Amemba et al. (2013). Such statements affirm the importance of ethics in supply chain functions. This is because supply chain functions mostly interrelate with the external world rather than the internal organisation. There is competition both by players in the internal organisation and in the external organisation. The competition is more severe in the external organisation environment since all external players are in the business market to win and make gains or profit. Supplies is one of the gateways that external players penetrate and exchange with the internal organisation or firm. To remark companies are now competing in supply chains rather than acquainted measures of business performance (Svensson and Båath, 2008). Ethics differs from law in that it is self-motivated and it achieves self-compliance automatically. Law or legal effectiveness necessitates responsibility and personal motivation. Responses of humans to ethical standards and practices are ideals (Ouedraogo, 2021). It is essential for all parties to behave ethically and adhere to the ethical ideology of supply chain practitioners and procurement professionals (Onyango, 2012; Olowa, 2018; Önder, 2018). The code of ethics spells out the road map through which firms operate to include making stakeholders commitments and staff ethical guidelines. Further ethical codes cover subjects that may not be covered by laws governing particular functions such as procurement and supply chain management (Elango et al., 2010). This helps to underline ethics importance in supply chain functions. Ethics implications in supply chain management functions has become paramount. Oluwafisoye and Akande (2013), noticed that most supply chain management staff had little or no formal training on ethics prior to being employed. Thus, the need to emphasis on the importance of ethics in supply chains and their functions considering that business transactions need to be conducted in avoidance of unethical acts. Unethical acts are themselves seen being exhibited in companies if not controlled by laws, rules and regulations or ensuring ethical standards at work place and functions in companies. 


\section{Literature Review}

This section of the study provides information on what supply chain functions and ethics in supply chain responsibilities are all about.

\subsection{Supply Chain Function}

The management of processes that involve; procurement of raw materials, transformation of finished goods and distribution of the finished goods to the final consumer is called supply chain management (SCM). Supply chain involves: producers, suppliers, buyers, transporters, customers and the final consumer. These mentioned are the simplest, the supply chains for manufacturing firms are usually complex because of the diverse nature of operations. Manufacturing firms usually require multiple suppliers and outsourcing operators than non-manufacturing (services) based firms. Thus, the supply chain function in a manufacturing firm is definitely more complicated than that of a service provider firm. The more complex the supply chain function is, the more is the need for ethical measures to streamline the supply chain and logistics operations from the producer to the final consumer. Streamlining processes at each step of the supply chain to make ensure that customers receive the right amount of the correct item or good at the right time and the correct information about goods, firms can benefit from proper supply chain management organisation. With deliveries need to be made on time and at the place, ethically supply chains oriented firms are likely to secure future businesses with both old and new customers, maintain and ensure market competitive advantage. A good enough supply chain management guarantees a balance between supply and demand. By ensuring effective, efficient and ethically apt supply chain management functions, profit can increase, goods be delivered on time, waste, administrative cost and legal cost reduced and time maximize. According to Jermsittiparsert and Srihirun (2019), the main purpose of supply chain is supply. While ethical supply is the standard measures put in place to proactively provide supply services and goods to customers.

Five (5) typically required functions of supply chain management both in manufacturing and nonmanufacturing firms include; purchasing, operations, logistics, resource management and information flow.

Purchasing: Purchasing is the very first function of supply chain management. Purchasing is performed by buyers or purchasers. Thus, it is vital that the raw materials are purchased and delivered on time to facilitate the timely production and delivery of the final goods. Any potential delays at any stage will lead to non-respect of business contracts. Thus coordination between buyers, sellers, suppliers and delivery companies and / or individuals is required to avoid any potential delays. Most important is to avoid any unethical practices between these players to avoid delays and extra costs on goods purchased.

Operations: In order to purchase materials forecasting and demand planning are required (Teseletso and Adachi 2021). This requires to determine the amount of goods to be produced and how much material is needed. The operations function is important in supply chain management to help avoid having surpluses or insufficiencies in stocks or inventory that may lead to loss of revenue and the final profit. To avoid further losses, it is essential to plan and forecast inventory, production and shipping activities.

Logistics: logistics synchronises the supply chain management activities of forecasting, planning, procurement, producing, warehousing and transporting products and goods to the final customer without encountering obstacles and distortion (Matto, et al., 2021). To facilitate quick shipment at low cost it is worthwhile to ensure effective and adequate communication within the supply chain comportments and system.

Resource Management: The resource management facilitates the allocation of the right activities in an optimized manner such that optimum production is achieve and operating efficiencies are maximised. Available capacity is calculated and the capability of resources are determined to ensure feasible and accurate orders and production are taking into consideration by the resource management team. This is essential since production consumes raw materials, technology, time and labour. In case of any production shortages, the extra material needed for adequate production need to be purchased and supplied.

Information System and Workflow: The distribution and sharing of information within supply chain management functions is what keeps them on track. The supply chain is broken when information communication and work flow are poor. A consistent and reliable information system can help prevent disruptions and increase 
visibility in information communication. This also ensures that every individual is working with the same data set to avoid miscommunications and ensure prompt update of people in the supply chain with current events and development. A good management information system (MIS) such as a supply software could be used to ensure visibility and communication in supply chains.

Although there are more than one supply chain functions, this study focuses on supply duties conducted by buyers, suppliers and companies involved in supply chains.

\subsection{Ethics in Supply Chain Responsibilities}

Ethics is important in supply chain functions to assist in reducing the risks in supplies activities, enhance culture and compliance practices of vendors (Anggay and Hamiche, 2021). Some companies ' code of ethics and conducts are expanded to apply to the whole supply chain function. Supply chain ethics includes practices such as; anti-bribery and corruption, humane and non-discriminatory treatment, safe and good hygienic working conditions, freedom of employment and association, environmental awareness, appropriate pay and working hours, eradication of child labour and child protection and abuse measures. Contrary behaviours to these would be viewed and considered unethical.

Ethical in one hand and on the other hand unethical contemplations are susceptible in procurement and supply chain management area. This is because the persons involved in the procurement and other supply chain functions are entrusted to spend good amount of financial resources in a number of organizations (Carter, 2000). Any contrary behavior to the entrusted and agreed is unethical. Procurement or buyers' professionals just as in sales or marketing functions deal greatly with part of the organization external environment. Consequently, the reputation of a firm is highly at risk when the performance of any supply chain management functions are conducted on unethical grounds (Amaeshi et al., 2008). Furthermore, supply chain function professionals cannot layoff their responsibility to monitor, control and select the supplier because of legal and ethical principles (Amaeshi et al., 2008). The goal of ethics in supply chain management function is to reduce the overall risk of the purchaser regarding corporate integrity failure in the supply chain (Keating, 2009).

To add value, ethical embeddedness is a very effective method, especially as the managers of supply faced ethical dilemmas more often (Eltantawy et al., 2009). Since the last few decades, organisations are taking the issue of supply chain performance and ethical responsibility very seriously (Benrqya and Jabboun, 2021; Beamon, 2005). This shows the need to respond to the need to act in a responsible way from the source of product to the end user (Carter and Jennings, 2004). Within the supply chain ethical practices are identified as a powerful means through which environmental and social organizational impacts can be proved (Hall and Matos, 2010). Organisational culture can add value to the organisation ethical behaviours. As mentioned by Smith and Hume (2005), it is very important for firms to understand the relationship between ethical values and organizational culture.

Ethical conduct is becoming more important to both buyers and suppliers. Buyer-supplier relationships play an important role in an organization's ability to respond to dynamic and unpredictable change. If the relationship is too restrictive, flexibility will be difficult to achieve and, if it is too lenient the risk of opportunism will be present. The literature in the area of supply management has begun recently to investigate ethical issues in buyer-supplier relationships (Turner et al., 1994). Therefore, the ethical conduct of the supply chains has also begun to be scrutinised, both from an internal business performance perspective, and from the increasing concerns held by the numerous stakeholders of the organisation (Yusuf, 2014). Supply management ethical responsibility is not directly affected by skills and has an indirect impact on performance through its positive relationship with perceived reputation Eltantawy et al., (2009). They further state that supply management ethical responsibility is limited in its ability to predict performance, but is a valuable component of building Supply management perceived reputation. Firms should not ignore supply management ethical responsibilities, as it may provide strategic marketing advantage as an order qualifier or limiting criterion. A study on supply chain management rated ethics to be the number one issue facing supply chain managers (Giunipero and Handfield, 2004). For example, one firm in the automobile, road construction, transport or aviation industry is a competitor, subcontractor and supplier to another firm in the same industry. These multiple relationships can create a complex web of information flows and contractual relationships that are all subject to potential supply chain management ethics problems. Although almost every company has 
some form of supply management ethics policy, the extent of deployment of these policies with supply management decisions can differ significantly (Murray, 2003). Much of the previous research implicitly defined supply management ethical responsibility as the avoidance of unethical behaviour. For example, Cooper et al. (1997) posit that supply management ethical responsibility involves;

- $\quad$ Accepting gifts and entertainment that affect buying decisions; and

- $\quad$ Failure to identify the customer's needs and recommend products and services that meet those needs.

- $\quad$ Allowing personalities to improperly influence the buying decision;

- $\quad$ Failure to provide prompt, honest responses to customers' inquiries and requests;

- $\quad$ Lack of knowledge or skills to competently perform one's duties;

- $\quad$ Avoidance of showing partiality toward suppliers preferred by upper management;

- $\quad$ Failure to provide products and services of the highest quality in the eyes of the internal customers;

Further, Flech (1985) posits that the sensitive practices involving standards of conduct in purchasing are sorted into nine categories. Of these categories, four represent avoidance of unethical supply management behaviour:

1. Reciprocity, or giving preference to a supplier who is also a customer; and

2. Personal purchases, which are clearly a misuse of trade discounts.

3. Acceptance of gifts;

4. Sharp practices, which, though short of fraud, are unscrupulous;

The five categories remaining represent broad areas in supply management where ethical dilemmas could arise frequently;

1. Presale technical or engineering services;

2. Everyday dealings with vendors; and

3. Competitive bidding;

4. Negotiation

5. Informal design or changes in production designs and specifications.

\section{Objective of the Study}

This study main objective is to examine the relationship between unethical behaviour and the significance of ethics in a supply chain function. This study is of particular significance as it helps in providing the literature much needed in the area of supply chain management and ethics. Considering the fact that Svensson and Båath, (2008) had observed that there is very little research conducted in the regard of ethics and supply chain.

\section{Research Methodology}

This area of the study narrates the various stages used in the research methodology of the study.

\subsection{Research Design for the study}

The study incorporates quantitative and qualitative approaches in research. Questionnaires that forms the qualitative aspect of the study were used to collect the need primary data. The quantitative aspect of the study made used of the primary data collected to test the hypotheses of the study. 


\subsection{Sampling Technique}

The data was collected using a random sampling technique administered on supply firms. This offer the opportunity for the respondents to be selected arbitrarily to complete the questionnaire. With this technique bias response is avoided and minimise. All respondents are given equal probability of being selected to attain to the questionnaire. Data collection and research time is greatly reduced in a random sampling technique since it is straight forward and simple to be administered.

\subsection{Study Research Framework}

In this study two variables are used to assess the relationship between unethical performance and the significant of ethics in a supply chain function. The variables include supply chain relationship (SCR) unethical act or conduct coded and keyed as (SCRUnethical) and implications of ethics in a supply chain function (SCF) coded and keyed as (ImplicationsEISCF).

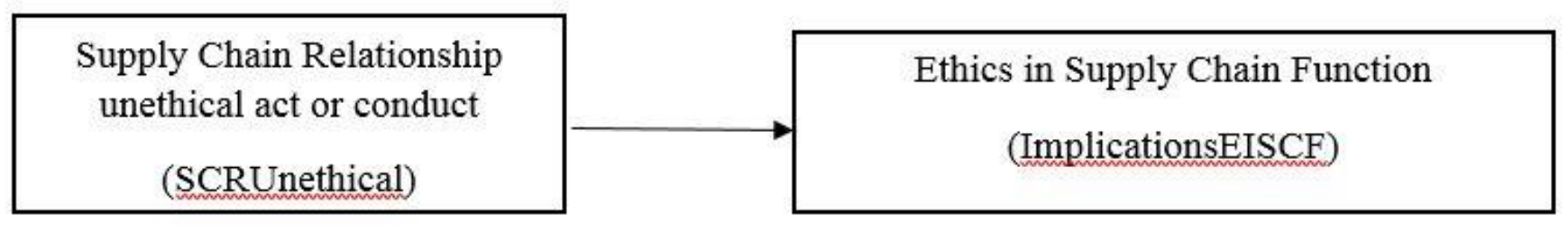

Figure 1. Research Framework

Based on the research framework, this study considers the following hypothesis;

$\mathrm{H1}$ : There is no relationship between unethical act and the significance of ethics in supply chain function.

\subsection{Research Technique Tool Used for the Study}

The evaluation technique used in this study include;

One-way Analysis of Variance (ANOVA) technique.

\subsection{Data Analysis}

The research data was coded and the data entry keyed in IBM SPSS 24 for data analysis (Burns and Burns, 2008). The output from the analyses were obtained, presented and interpreted.

The study assesses the relationship between acting unethical in a supply chain and the significance of ethics in supply chain functions using the following evaluation technique;

ANOVA: ANOVA is being used to test for differences in means between groups and within groups. The data generate an F-test statistic which corresponds to a p-value. The p-value is compared to significance level of 0.05 . Where the obtained $p$-value is less than the significance level of 0.05 , the research hypothesis is rejected. This means there is a difference in the means groups between groups and within groups of the respondents.

\section{Results}

This area of the study presents the descriptive and empirical results of the study.

\subsection{Descriptive results}

The descriptive results consist of; respondent statistics, distribution of perpetuators of unethical conduct in supply chains and assessment of implication of ethics in supply chain function. Percentages and ranking are used to measure, differentiate and present results in this section. 


\subsubsection{Respondents Statistics}

From table 1, 30 respondents submitted their feedback to questions on supply chain relationship (SCR) unethical conduct and the implication of ethics in a supply chain function (SCF).

Table 1. Respondents Statistics

\begin{tabular}{|cc|c|c|}
\hline & & SCRunethical & ImplicatinsEISCF \\
\hline \multirow{2}{*}{$\mathrm{N}$} & Valid & 30 & 30 \\
& Missing & 0 & 0 \\
\hline
\end{tabular}

\subsubsection{Distribution of Unethical Conduct in Supply Chains}

From table 2,6.7\% of the respondents indicated that supply chain relationship unethical behaviours in initiated by suppliers, $56.7 \%$ indicated that it is initiated by buyers, while some $23.3 \%$ indicated that unethical behaviours are initiated by the company. Finally, $13.3 \%$ of the respondents indicated that unethical behaviours in supply relationship are initiated by all (that is: suppliers, buyers and the company or firm) the players or parties involved in supply chain relationship.

Table 2. Distribution of Unethical Conduct in Supply Chains

\begin{tabular}{|c|c|c|c|c|}
\hline Supply Chain Parties & Frequency & Percent & Valid Percent & Cumulative Percent \\
\hline Suppliers & 2 & 6.7 & 6.7 & 6.7 \\
Buyers & 17 & 56.7 & 56.7 & 63.3 \\
Valid $\quad$ the Company & 7 & 23.3 & 23.3 & 86.7 \\
& 4 & 13.3 & 13.3 & 100.0 \\
All & 30 & 100.0 & 100.0 & \\
Total & 30.0 & \\
\hline
\end{tabular}

\subsubsection{Assessment of Implication of Ethics in Supply Chain Function}

From table 3 on the affirmation of the implication of ethics in supply chain functions, $53.3 \%$ of the respondents indicated that ethics have implications in a supply chain function. Some $26.7 \%$ of the respondents directed that ethics does not have implications in a supply chain function. Another $20.0 \%$ of the respondents signposted their doubts whether or not ethics and ethical behaviour has a place in a supply chain function.

Table 3. Affirmation of Implication of Ethics in Supply Chain Functions

\begin{tabular}{|c|c|c|c|c|c|}
\hline \multicolumn{2}{|c|}{ Affirmation } & Frequency & Percent & Valid Percent & Cumulative Percent \\
\hline \multirow{4}{*}{ Valid } & Yes & 16 & 53.3 & 53.3 & 53.3 \\
\hline & No & 8 & 26.7 & 26.7 & 80.0 \\
\hline & Not Sure & 6 & 20.0 & 20.0 & 100.0 \\
\hline & Total & 30 & 100.0 & 100.0 & \\
\hline
\end{tabular}

From table 4 on the implication of ethics in a supply chain function, long term partner relationship is ranked first with $30 \%$ of the respondents' affirmation. Cost saving is ranked second with $23 \%$. Delivering of the right goods and quantity is ranked third with $20 \%$. Defect or spoilage control and minimization is ranked fourth with $17 \%$. And finally others categories to include trust, easy and through procedures are ranked fifth with $10 \%$. 
Table 4. Implication of Ethics in a Supply Chain Function

\begin{tabular}{|l|l|l|}
\hline Implication detail & Percentage Feedback (\%) & Rank \\
\hline Long term relationship & $30 \%$ & 1 \\
\hline Cost saving & $23 \%$ & 2 \\
\hline Delivering of the right goods and quantity & $20 \%$ & 3 \\
\hline Defect or Spoilage Control and Minimization & $17 \%$ & 4 \\
\hline Others; trust, straight through procedures or processes etc. & $10 \%$ & 5 \\
\hline
\end{tabular}

\subsection{Empirical Results}

This section shows the results of the hypothesis testing using ANOVA evaluation techniques to assess the relationship between unethical act and the implication of ethics in supply chain functions.

\subsubsection{Relationship between unethical act and the significant of ethics in supply chain functions}

\subsubsection{ANOVA Technique of Evaluation}

Looking at table 5, with the F-test statistics p-value of .686 which is by far greater than the significance level of .05 , the null hypothesis which states that there is no relationship between to act unethical and the importance of ethics in a supply chain function is accepted. Thus, the study did not find sufficient evidence to indicate the existence of a relationship between unethical behaviours and the significance of ethics in a supply chain function in a firm.

Table 5. ANOVA assessment of Supply Chain Relationship Unethical Act in Supply Chain Functions

\begin{tabular}{|c|c|c|c|c|c|}
\hline & Sum of Squares & $\mathrm{df}$ & Mean Square & $\mathrm{F}$ & Sig. \\
\hline Between Groups & .533 & 2 & .267 & .382 & .686 \\
Within Groups & 18.833 & 27 & .699 & & \\
Total & 19.367 & 29 & & & \\
\hline
\end{tabular}

\section{Discussion of Results}

For the fact that none of the parties in a supply chain has a score of zero, it only means that unethical conduct in supplies is practice by all parties in the supply chain.

In a supply chain, buyers are the most likely to initiate an unethical conduct. This falls in line with the philosophy that you need to offer incentives to those occupying purchasing functions in companies in order for them to buy your goods or advice their company to buy your goods. However, the burden of unethical acts or behaviours should not be on buyers alone. Supply chain relationship has at least two parties in the chain. Suppliers too are involved in unethical conduct in supply as the study results show a small percentage of suppliers' involvement in unethical supplies. Besides the law of exchange holds, that there should be offer and acceptance. It means that if buyers make an offer, there should be another partner in the supply chain to accept the offer for any unethical act to be completed. There are strong motives for staying ethical in supply chain relationship because of the benefits good ethics ensure in a supply chain. They include; Long term partner relationship, cost savings, delivering of right orders, goods and quantity, defect or spoilage control and minimization, trust, confidence, quality assurances, integrity and straight through procedures or processes (Pretious and Love, 2006; Auroi, 2003).

In this study long term partner relationship ranked top followed by cost savings. Long term relationship in supplies is would ensure easy collaboration and easy contract renewals and less training thus resulting in financial gains (Feng, 2021; Derwik and Hellstrom, 2021). This is in line with (Hoyt and Huq, 2000; Zadek, 1998) assertion 
that financial benefit can be gained by long-term partnerships between the firms and supply chains. Cost savings play a part in increasing business financial gains (Bandara, 2021). Cost savings on storage, logistics, insurance fees, loss of business and streamline production and services delivery processes influence by ethical supply culture can greatly increase business operating profit that would impact the end financial position of the company positively.

Finally, the test result shows no sufficient evidence to signpost the existence of a relationship between unethical conduct and the application of ethical values in supply chain functions. Whether an organisation has ethical rules guiding its supply chain functions and operations or not, perpetuators of unethical acts are likely to act the way they wish or desire. Except some form of further training on the importance of ensuring ethical standards and job placement and not fines or penalties can ensure complete adherence to ethical supply principles in supply chains.

\section{Conclusion}

The importance of ethics in supply chain functions include; Long term relationship, cost savings, delivering of the right goods and quantity, defect or spoilage control and minimization, trust, confidence, quality assurances, integrity and reputation sustainability. Among these benefits of ethical supplies, long term relationship and cost savings are ranked top because of the financial advantages they offer. These benefits can help avoid and reduce unethical conduct. Unethical conduct is an intentional act of willingness by the perpetuators in a supply chain relationship for their gain. This study is useful for all business entities that are involved with supply responsibilities to help them see the need to promote good ethical behaviours in their supply chain management functions. An ethically lead supply firm would attract new partners easily and attract successful both short and long term business deals.

\section{References}

Amaeshi, K.M., Osuji O.K., Nnodim, P., (2008), Corporate social responsibility in supply chains of global brands: A boundaryless responsibility? Clarifications, exceptions and implications, Journal of Business Ethics, 81(1), 223-234. https://doi.org/10.1007/s10551-007-9490-5

Amemba, C.S., Nyaboke, P.G., Osoro A., Mburu, N., (2013), Challenges affecting public procurement performance process in Kenya, International Journal of Research in Management, 3(4), 41-55.

Anggay, A., Hamiche, M., (2021) Social compliance of enterprises in developing countries between requirements and practices (audit of labour health and security conditions: case of Morocco). African Journal of Economic and Sustainable Development, 8(3) 239-256. https://doi.org/10.1504/AJESD.2021.116638

Auroi, C., (2003), Improving sustainable chain management through fair trade, Greener Management International, Autumn, No. 43, 25-35.

Bandara, D., (2021). Determining optimal locations of distribution centers to minimize transportation costs. International Journal of Supply Chain and Inventory Management, 4(1) 42-58. https://doi.org/10.1504/IJSCIM.2021.114740

Beamon, B.M., (2005), Environmental and sustainability ethics in supply chain management, Science and Engineering Ethics, 11(2) 221-234. https://doi.org/10.1007/s11948-005-0043-y

Benrqya, Y., Jabboun, I., (2021). Performance evaluation of European grocery retailers: a financial statement analysis, International Journal of Logistics Economics and Globalisation, 9(1) 24-39. https://doi.org/10.1504/IJLEG.2021.10039482

Burns, R.P. \& Burns, R., (2008) Business research methods \& statistics using SPSS. SAGE Publications, UK.

Carter, C.R., Jennings, M.M. (2004), The role of purchasing in corporate social responsibility: A structural equation analysis, Journal of Business Logistics, 25(1), 145-186. https://doi.org/10.1002/j.2158-1592.2004.tb00173.x

Carter, C.R., (2000), Ethical issues in international buyer-supplier relationships: A dyadic examination, Journal of Operations Management, 18(2) 191-208. https://doi.org/10.1016/S0272-6963(99)00016-9

Cooper, R.W., Frank, G.L., Kemp, R.A., (1997), The ethical environment facing the profession of purchasing and materials management, International Journal of Purchasing and Materials Management, 33(2) 2-13. https://doi.org/10.1111/j.1745-493X.1997.tb00286.X 
Derwik, P., Hellstrom, D., (2021), How supply chain professionals learn at work: an investigation of learning mechanisms, International Journal of Physical Distribution \& Logistics Management, 51(7) 738-763. https://doi.org/10.1108/IJPDLM-11-2019-0335

Elango, B., Paul, K., Kundu S.K., Paudel, S.K., (2010), Organizational ethics, individual ethics, and ethical intentions in international decision-making, Journal of Business Ethics, 97(4) 543-561. https://doi.org/10.1007/s10551$\underline{010-0524-Z}$

Eltantawy, R.A., G.L. Fox and L. Giunipero, (2009), Supply management ethical responsibility: Reputation and performance impacts, Supply Chain Management: An International Journal, 14(2), 99-108. https://doi.org/10.1108/13598540910941966

Feng, X., (2021), Economic and Ecological Optimization of the London Urban Logistics System Considering Infection Risk during Pandemic Periods, International Journal of Supply and Operations Management, 8(2) 114-133. http://dx.doi.org/10.22034/ijsom.2021.2.2

Flech, R.I., (1985), Standards of conduct: the key to supplier relations, Journal of Purchasing and Materials Management, 21(3) 16-18. https://doi.org/10.1111/j.1745-493X.1985.tb00137.x

Giunipero, L., Handfield, R.B., (2004), Purchasing Education and Training II, CAPS Research, Tempe, AZ.

Hall, J., Matos, S., (2010), Incorporating impoverished communities in sustainable supply chains, International Journal of Physical Distribution \& Logistics Management, 40(1/2), 124-147. https://doi.org/10.1108/09600031011020368

Hoyt, J., Huq, F., (2000), From arms-length to collaborative relationships in the supply chain: An evolutionary process, International Journal of Physical Distribution \& Logistics Management, 30(9), 750-764. https://doi.org/10.1108/09600030010351453

Jermsittiparsert, K., Srihirun, W., (2019), Role of Ethics in Supply Chain Management: Culture as Moderator, Humanities \& Social Sciences Reviews, 7(3) 736-743. https://doi.org/10.18510/hssr.2019.73105

Keating, B., (2009), Managing ethics in the tourism supply chain: The case of Chinese travel to Australia, International Journal of Tourism Research, 11(4), 403-408. https://doi.org/10.1002/jtr.706

Matto, M.C., Ame, A.M., Nsimbila, P.M., (2021). Tender process and value for money in Tanzania public procurement, International Journal of Logistics Economics and Globalisation, 9(1), 1-23. https://doi.org/10.1504/IJLEG.2021.116218

Murray, J.E., (2003), When you get what you bargained for - but don't, Purchasing, 32(4) 26-27.

Olowa, O.W., (2018), Determinants of rural residential solid waste collection services in lagos state, International Journal of Sustainable Development \& World Policy, $7(1) \quad$ 1-7. https://doi.org/10.18488/journal.26.2018.71.1.7

Oluwafisoye, O., Akande, O., (2013), Business ethics and corporate social responsibility. The Perception of Employees on Business Ethics in an Organization.

Önder, M., (2018). Contribution of plays and toys to children's value education, Asian Journal of Education and Training, 4(2), 146-149. https://doi.org/10.20448/journal.522.2018.42.146.149

Onyango, J.P., (2012), Role of ethics in supply chain management of oil marketing firms in Kenya, Project Research Presented to the University of Nairobi, School of Business, Nairobi.

Ouedraogo, F., (2021), Collective beliefs and representations on the effects of rice price and subsidy policies in Burkina Faso. African Journal of Economic and Sustainable Development, 8(3) 209-229. https://doi.org/10.1504/AJESD.2021.116642

Pretious, M., Love, M., (2006), Sourcing ethics and the global market: the case of the UK retail clothing sector, International Journal of Retail and Distribution Management, 34(12) 892-903. https://doi.org/10.1108/09590550610714620

Smith, A., Hume, E.C., (2005), Linking culture and ethics: A comparison of accountants' ethical belief systems in the individualism/collectivism and power distance contexts, Journal of Business Ethics, 62(3) 209-220. https://doi.org/10.1007/s10551-005-4773-1

Svensson, G. and H. Bååth, (2008), Supply chain management ethics: Conceptual framework and illustration. Supply Chain Management: An International Journal, 13(6) 398-405. https://doi.org/10.1108/13598540810905651

Teseletso, L.S., Adachi, T., (2021), Strategic planning of coal assets for electricity production: a case of Botswana. African Journal of Economic and Sustainable Development, 8(3) 185-208. https://doi.org/10.1504/AJESD.2021.116630 
Turner, G.B., Taylor, G.S. Hartley, M.F., (1994), Ethics policies and gratuity acceptance by purchasers, International Journal of Purchasing and Materials Management, 30(3) 43-7. https://doi.org/10.1111/j.1745493X.1994.tb00196.X

Yusuf, Y., Hawkins, A., Musa, A., El-Berishy, N., Schulze, M. and Abubakar, T., (2014), 'Ethical supply chains: analysis, practices and performance measures', International Journal of Logistics Systems and Management, 17(4), 472-497. https://doi.org/10.1504/IJLSM.2014.061016

Zadek, S. (1998) Balancing performance, ethics, and accountability, Journal of Business Ethics, 17(13) 1421-1442. https://doi.org/10.1023/A:1006095614267

Does this article screened for similarity: YES

Funding: No funding was received for conducting this study.

Conflict of Interest: The authors have no conflicts of interest to declare that they are relevant to the content of this article.

\section{About The License}

(C) The author(s) 2021. The text of this article is open access and licensed under a Creative Commons Attribution 4.0 International License

\section{Cite this Article}

Sunday Agbor Mbu \& Maurice Ayuketang Nso, Implication of Ethics in Supply Chain Function, Asian Journal of Interdisciplinary Research, 4(3) (2021) 44-53. https://doi.org/10.34256/ajir2135 